\title{
Surgery for early stage hepatocellular carcinoma
}

\author{
Luis Cesar Bredt, Tiago Cesar Mierzwa, Alex Francovig Rachid, \\ Francisco Guilherme Fernandes, Julio Cezar Zanini
}

\begin{abstract}
Hepatocellular carcinoma (HCC) is the third leading cause of cancer-related death worldwide, and the curative treatment is available only for tumors detected in early stage. In a critical analysis of the therapeutic options in early stage HCC three potential curatives therapies are possible in early stage HCC: total hepatectomy with liver transplantation (LT), partial hepatectomy and radiofrequency ablation (RFA) of very small tumors. Total hepatectomy with LT has proven to be the best treatment for operable and resectable disease (BCLC o and $A$ ) in a cirrhotic liver, the liver resection, RFA, transarterial chemoembolization (TACE) or percutaneous injection of alcohol (PIA) can be considered for those patients with waiting list time up to six months. Partial hepatectomy as definitive therapy should be used only for patients with patients in Child-Pugh $A$ and $B$ without portal hypertension. In patients with
\end{abstract}

Luis Cesar Bredt ${ }^{1}$, Tiago Cesar Mierzwa ${ }^{1}$, Alex Francovig Rachid ${ }^{1}$, Francisco Guilherme Fernandes ${ }^{1}$, Julio Cezar Zanini $^{1}$

Affiliations: ${ }^{1}$ Department of Abdominal Surgery, Hepatobiliary Section, Cancer Hospital-UOPECCAN, Cascavel, PR, Brasil.

Corresponding Author: Luis César Bredt, Rua Dom Pedro II, 2099, ap 701, Centro, Cascavel, Paraná, Brasil, Postal Code: 85812-270; Ph: +55(45) 9936-9943; Fax: +55(45)2101-7005; Email: Icbredt@gmail.com

Received: 12 April 2015

Accepted: 02 June 2015

Published: 02 July 2015 inoperable but localized disease (BCLC A), the RFA or PIA can be indicated.

Keywords: Early Stage, Hepatocellular carcinoma, Therapeutic options, Curative treatments

\section{How to cite this article}

Bredt LC, Mierzwa TC, Rachid AF, Fernandes FG, Zanini JC. Surgery for early stage hepatocellular carcinoma. Int $\mathrm{J}$ Hepatobiliary Pancreat Dis 2015;5:47-55.

Article ID: 100033IJHPDLB2015

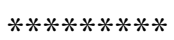

doi:10.5348/ijhpd-2015-33-RA-8

\section{INTRODUCTION}

Hepatocellular carcinoma (HCC) is the sixth most common type of cancer worldwide and the leading cause of death among patients with cirrhosis [1]. Most patients with HCC are cirrhotic due to viral hepatitis or hepatic disease induced by alcohol, but more recent data suggests that the metabolic syndrome associated with non alcoholic liver disease may be an important cause of HCC. The molecular pathogenesis of HCC is extremely complex and heterogeneous, and to date the molecular information has not impacted on treatment decisions [2].

Various HCC staging systems applied in clinical practice and prognostic assessment classifications have been proposed, including the Child-Pugh classification [3], the Index of Cancer of the Liver Italian Program 
(CLIP) [4], Barcelona Clinic Liver Cancer (BCLC) staging [5], Grouped'Etude et Traitement du Carcinome Hépatocellulaire (GETCH) [6], Chinese University Prognostic Index (CUPI) [7], Japan Integrated Staging (JIS) score [8], modified JIS (mJIS) score [9], Okuda staging [10], the Tokyo score [11], and the Model for End-Stage Liver Disease (MELD) stratification system for organ allocation [12].

The BCLC staging system [5] has been proposed as the standard method for the assessment of prognosis and therapeutic orientation in Europe and the United States $[13,14]$, it classifies patients into five stages and includes Child-Pugh [3], Okuda [10], TNM classifications [15] and performance status scoring [16]. The consensus of the American Hepato-Pancreato-Biliary Association (AHPBA) in 2010 has pointed to the BCLC classification as suitable for therapeutic recommendation [17], and the accurate stage evaluation is essential for assessing tumor resectability, therapy choice and prognosis.

Therapeutic approaches to HCC can be classified into three categories: potentially curative, palliative and symptomatic, according to patients different stages, adopting tumor burden, liver function and physical status as criteria. Each stage is linked to the first-line treatment option that is proposed according to the available scientific evidence [2]. Less than $20 \%$ of cases are potentially eligible for potentially curative treatment $[18,19]$, with the majority of patients with HCC being thrilled to symptomatic or palliative treatment.

In the specific scenario of early stage HCC, the diagnostic criteria for these lesions have been welldefined (including nodules between 1 and $2 \mathrm{~cm}$ ) and widely accepted, and the most important is that effective treatment is available for tumors detected at an early stage [2].

Potentially curative treatments for early tumors usually include surgical modalities, such as hepatic resection and liver transplantation, with promising survival rates up to $75 \%$ at 5 years [20].

\section{Resection versus Ablation for Very Early Stage HCC}

In the context of early stage lesions, a very early $\mathrm{HCC}$ is defined as asymptomatic solitary HCC with a diameter of $<2 \mathrm{~cm}$, and the treatment recommended by the European Association for the Study of Liver and American Association for the Study of the Liver (EASLAASLD) for patients presenting with HCC in very early stage and liver function Child-Pugh $\mathrm{A}$ is resection, with an overall and recurrence-free survival rates at five years after liver resection of 70 and 68\%, respectively. However, the radiofrequency ablation (RFA) can achieve equal acceptable outcomes for very early HCC, with 5-years disease-free survival of $62 \%$ and 5 -years overall survival of $78 \%$. Moreover, it have been suggested that RFA should be considered as first-line therapy, even when resection is possible, because it is associated with fewer side effects, but whether surgical resection is superior to RFA remains controversial [14, 21].

Wang et al. [22] suggested that although surgical resection was equivalent to RFA in terms of overall survival, the resection provided a free survival at five years of $40.7 \%$ against $29.3 \%$ of disease patients with RFA ( $p=0.006)$. However, Peng et al. [23] reported that RFA was associated with better overall survival compared with surgical resection, and the overall five-year survival was $71.9 \%$ with RFA and $62.1 \%$ with surgical resection, concluding that the FRG was more effective and safe in patients with HCC smaller than $2 \mathrm{~cm}$. Therefore, more trials are needed before RFA may be recommended as first-line therapy for very early $\mathrm{HCC}$ as a substitute for surgical resection.

\section{Liver Transplantation And Resection For Early Stage HCC}

Early stage HCC is defined according to the Milan criteria [24] as follows: a single tumor nodule $\leq 5 \mathrm{~cm}$ in diameter or $\leq 3$ nodules $\leq 3 \mathrm{~cm}$ in diameter, and the best candidates for liver transplantation are those with liver cirrhosis and only $<5 \mathrm{~cm}$ tumor or up to three tumors $<3$ $\mathrm{cm}$, without signs of vascular invasion or extrahepatic disease (Milan criteria), with an overall survival of $85 \%$ at 4 years $[24,25]$. The presence of tumor $>5 \mathrm{~cm}$, vascular invasion, poorly differentiated tumors and lymph node metastasis are important negative predictive factors that contraindicate conventional liver transplantation [26, 27].

According to the EASL-AASLD guidelines [14], the ideal approach for early stage HCC is liver transplantation, but RFA can be a substitute when transplantation is not feasible, and liver resection should be considered when patients present with a solitary tumor without portal hypertension [13]. Farinati et al. [28] reported that for patients with early stage HCC, liver transplantation offers the best chance of survival (106 months) compared to surgical resection (52 months), RFA (62 months), percutaneous ethanol injection (PEI, 44 months), and transarterial chemoembolization (TACE, 34 months). In a recent meta analysis [29] the five-year survival after liver transplantation for early stage HCC was $63 \%$, whereas previous reports presented heterogeneous results [3045]. A recent analysis of the International Registry of Hepatic Tumors Transplant [46] demonstrated in the last 20 years there has been an increase in the cure rate and a reduced morbidity (Table 1 ).

Both in America and in Europe the number of patients waiting for a liver exceeds the number of performed transplants per year, less than one patient out of three of those enlisted receives LT [47]. Clearly, the selection of patients according to risk of recurrence and morbidity/ mortality with the procedure is essential to optimize the use of the few available organs [48].

After the implementation of the Milan Criteria [24] the number of LTs for HCC has increased worldwide and 
Table 1: Selected series of liver transplantation for early stage hepatocellular carcinoma (HCC) since 2000

\begin{tabular}{llll} 
Study (year) & $n$ & $\begin{array}{l}\text { Five-year } \\
\text { Survival }\end{array}$ & $\begin{array}{l}\text { Operative } \\
\text { Mortality (\%) }\end{array}$ \\
\hline Iwatsuki (2000) [30] & 344 & $49 \%$ & - \\
Tamura (2001) [31] & 53 & $61 \%$ & - \\
Hemming (2001) [32] & 112 & $57 \%$ & 13 \\
Jonas (2001) [33] & 120 & $59 \%$ & 1.7 \\
Figueras (2001) [34] & 307 & $63 \%$ & - \\
Yao (2001) [35] & 60 & $75 \%$ & 1,4 \\
Gondolesi (2004) [36] & 36 & $45 \%$ & 22 \\
Zavaglia (2005) [37] & 155 & $72 \%$ & 11 \\
Takada (2006) [38] & 93 & $64 \%$ & - \\
Cherqui (2009) [39] & $18^{\mathrm{a}}$ & $70 \%$ & 0 \\
Coelho (2009) [40] & 45 & 4 & 0 \\
\hline Lee (2010) [41] & 78 & $68 \%$ & 5.1 \\
Vibert, (2010) [42] & 153 & $72 \%$ & 2 \\
Koniaris (2011) [43] & 326 & $53 \%$ & - \\
Sandhu, (2012) [44] & 282 & $75 \%$ & - \\
Rahman (2012) [45] & 1290 & $65 \%$ & - \\
\hline Salvage trarrences & \\
\hline
\end{tabular}

a Salvage transplantation after resection,

${ }^{\mathrm{b}}$ From time of transplantation

currently in Europe about $27 \%$ of all LT patients have HCC [49]. Thus, major emphasis has been placed on policies and priorities regarding waiting list management [50-53], but the heterogeneity of tumor presentation and the variability of response to treatments impedes an accurate prediction of progression. The controversies persist and no strategy has been uniformly adopted [2].

The best candidates for surgical resection are the exclusive Child-Pugh A patients with normal bilirubin values, the absence of clinical signs of portal hypertension (platelet count, splenomegaly and esophageal varices), only tumor diameter $<5 \mathrm{~cm}$ (without vascular invasion), asymptomatic and MELD $<8$ [5456]. Hyperbilirubinemia, portal hypertension and clinical deterioration criteria should be considered inoperable despite the resectability [57].

The extent of resection depends on the patient's liver function, and in case of absence of cirrhosis, up to two thirds of the liver can be removed surgically. A useful tool for evaluation of marginal candidates for liver resection is testing of indocyanine green clearance, and the portal vein embolization may be useful in the induction of hepatic hypertrophy, when the estimated volume of remaining liver is insufficient. Larger lesions (T2 tumors), when possible, should be treated with major hepatic resections, since these enlarged surgical resections are associated with increased progression-free survival [58].
Tumor recurrence in those patients undergoing partial hepatectomy for HCC is predominantly intra-hepatic, and usually occurs in the first three years of follow-up [59]. The five-year survival with surgery is variable according the recent series of liver resection for $\operatorname{HCC}[39,41,44,45$, 60-73], and in the specific scenario of early stage HCC, Dhir et al. [29] described in his metanalysis a five-year survival of $53 \%$ (Table 2).

Worldwide the approach to resection versus transplantation varies depending upon local resources, expertise and donor availability. The results of resection and transplantation are difficult to summarize since not a single surgical modality may fit all HCC presentations, being individual components of the patients crucial for decision making [2].

Resection and transplantation achieve the best outcomes in well-selected candidates (five-year survival of $60-80 \%)$ and compete as the first option in patients with early tumors and well-preserved liver function on an intention-to-treat analysis [68]. Recent metaanalysis showed that both surgical resection and liver transplantation are options with curative potential in patients with early stage HCC without cirrhosis or well compensated cirrhosis, with survival at five years

Table 2: Selected series of hepatic resection for early stage hepatocellular carcinoma (HCC) since 2000

\begin{tabular}{|c|c|c|c|}
\hline Study & $n$ & $\begin{array}{l}\text { Five- } \\
\text { year } \\
\text { Survival } \\
(\%)\end{array}$ & $\begin{array}{l}\text { Operative } \\
\text { Mortality } \\
(\%)\end{array}$ \\
\hline Zhou (2001) [6o] & 1000 & 63 & 1.5 \\
\hline Grazi (2001) [61] & 264 & 42 & 4.9 \\
\hline Yamamoto (2001) [62] & 58 & 62 & - \\
\hline Poon (2002) [63] & 135 & 70 & 3.7 \\
\hline Wayne (2002) [64] & 249 & 41 & - \\
\hline Grazi (2003) [65] & 308 & 42 & 4.9 \\
\hline Ercolani (2003) [66] & 224 & 42 & - \\
\hline $\mathrm{Hu}(2005)[67]$ & 154 & - & - \\
\hline Pawlik (2005) [68] & 300 & 27 & 5 \\
\hline $\mathrm{Wu}(2005)$ [69] & $\begin{array}{l}161(1991-96) \\
265(1997-02)\end{array}$ & $\begin{array}{l}28.2 \\
34\end{array}$ & $\begin{array}{l}3 \cdot 7 \\
0.4\end{array}$ \\
\hline Taura (2007) [70] & 166 & 46 & 4 \\
\hline Yamashita (2007) [71] & 59 & 71 & - \\
\hline Cherqui (2009) [39] & 67 & 72 & 4.5 \\
\hline Lee (2010) [41] & 130 & 52 & 0.8 \\
\hline Koniaris (2011) [44] & 326 & 62 & - \\
\hline Belghiti (2012) [72] & 138 & 77 & 1.4 \\
\hline Hasegawa (2012) [73] & 5361 & 71,5 & - \\
\hline Rahman (2012) [45] & 989 & 56 & - \\
\hline
\end{tabular}


58\% (transplantation: 63\%; surgery: 53\%) [55]. In a retrospective study comparing surgical resection versus transplantation for patients with early stage HCC, MELD $\leq 8$ and no evidence of hepatitis there was no statistical difference $(p=0.21)$ in survival at five years (41 versus $69 \%$, respectively) [56]. When assessing the cost impact of the proposed treatment and its effectiveness, liver transplantation is beneficial if performed between 6 and 12 months of waiting, and liver resection is favored those whose transplant is scheduled waiting more than 18 months $[74,75]$.

Cirrhotic patients eligible for liver transplantation and who have resectable lesions and favorable clinical criteria for resection (portal vein pressure $<10 \mathrm{mmHg}$, absence of thrombocytopenia and preserved liver function) should also be considered initially for curative liver resection [76-78]. The age can be a limiting factor for liver transplant, which should be restricted to patients in good physical condition and below 70 years of age.

As commented, despite the excellent efficacy of LT in treatment of early stage HCC, the shortage of donor livers or the drop out in the waiting list because of progression leads to the necessity of alternative therapies for early stage HCC meeting Milan criteria, such as RFA or resection, when feasible. Although a recent meta-analysis have pointed surgical resection as a superior modality of therapy compared to RFA in terms of overall survival, recurrence-free survival, and local recurrence rate, the analysis was primarily based on non-randomized studies, so the superiority of surgical resection remains controversial. In this scenario, liver resection can serve as a "bridge" for LT while the patient awaits a donor liver, being the radiofrequency ablation a similar alternative in non-superficial nodules away from the biliary bifurcation. In these situations, the hepatectomy offers advantages over RFA regarding the assessment of some specific histological tumor characteristics that may serve to better define the indications for LT, such as vascular invasion, however, there is no consensus on how to use these results. Moreover, LT can eventually provides the best rescue strategy for patients who suffer recurrence after resection meeting Milan criteria [56, 78-80].

In patients with inoperable for partial or total hepatectomy, but still with early disease (BCLC A), the RFA or, in selected cases, percutaneous injection of alcohol (PIA) can be indicated. PIA is particularly restricted for patients with tumors $<3 \mathrm{~cm}$, and less than three tumors in the absence of ascites [81-83]. A study comparing 102 patients randomized for RFA or PIA showed that the twoyear survival was similar in both groups (98 versus $88 \%$, $\mathrm{p}=0.14$ ), but the disease-free survival was better in the RFA group (64 versus 43\%, $p=0.012$ ) [84]. These results were confirmed by three other randomized studies of RFA versus PIA, and a meta-analysis [85-88]. However, the PIA is preferable to RFA in lesions near to bile ducts (lesions mainly located in segment IV) or bowel, due the risk of biliary or intestinal damage [89].
A prospective randomized trial with 189 patients evaluated the treatment with RFA with or without TACE of lesions $\leq 7 \mathrm{~cm}$, with increased overall $(\mathrm{HR}=0.525$, $\mathrm{p}=0.002)$ and disease $=$ free survival $(\mathrm{HR}=0.575$, $\mathrm{p}=0.009$ ) in the combined treatment group, suggesting that this strategy may be useful [90].

\section{CONCLUSION}

Three potential curatives therapies are possible in early stage Hepatocellular carcinoma (HCC): total hepatectomy with liver transplantation (LT), partial hepatectomy and radiofrequency ablation (RFA) of very small tumors. Total hepatectomy with LT has proven to be the best treatment for operable and resectable disease (BCLC $\mathrm{O}$ and $\mathrm{A}$ ) in a cirrhotic liver, reducing the risk of recurrence and liver failure, mainly when the waiting list is less than six months, the liver resection, RFA, transarterial chemoembolization (TACE) or percutaneous injection of alcohol (PIA) can be considered for those patients with waiting list time up to six months. Partial hepatectomy as definitive therapy should be used only for patients with preserved liver function, therefore, patients in Child-Pugh A and B without portal hypertension. In patients with inoperable but localized disease (BCLC A), the RFA can be a option, or in selected cases, the PIA can be indicated.

$* * * * * * * * *$

\section{Author Contributions}

Luis Cesar Bredt - Substantial contributions of Conception and design, acquisition of data; revising it critically for important intellectual content; final approval of the version to be published

Tiago Cesar Mierzwa - Substantial contributions of Conception and design, acquisition of data, Analysis and interpretation of data, drafting the article; final approval of the version to be published

Alex FrancovigRachid - Substantial contributions of Conception and design, acquisition of data, drafting the article; final approval of the version to be published

Francisco GuilhermeFernandes - Analysis and interpretation of data; revising it critically for important intellectual content; final approval of the version to be published

Julio Cezar Zanini - Analysis and interpretation of data; revising it critically for important intellectual content; final approval of the version to be published

\section{Guarantor}

The corresponding author is the guarantor of submission.

\section{Conflict of Interest}

Authors declare no conflict of interest. 


\section{Copyright}

(C) 2015 Luis Cesar Bredt et al. This article is distributed under the terms of Creative Commons Attribution License which permits unrestricted use, distribution and reproduction in any medium provided the original author(s) and original publisher are properly credited. Please see the copyright policy on the journal website for more information.

\section{REFERENCES}

1. Tabrizian P, Roayaie S, Schwartz M E. Current management of hepatocellular carcinoma. World J Gastroenterol 2014;20(30):10223-37.

2. Bruix J, Gores GJ, Mazzaferro V. Hepatocellular carcinoma. clinical frontiers and perspectives. Gut 2014;63(5):844-55.

3. Pugh RN, Murray-Lyon IM, Dawson JL, Pietroni MC, Williams R. Transection of the oesophagus for bleeding oesophageal varices. Br J Surg 1973;60(8):646-9.

4. The Cancer of the Liver Italian Program (CLIP) investigators: A new prognostic system for hepatocellular carcinoma: A retrospective study of 435 patients. Hepatology 1998;28:751-55.

5. Llovet JM, Brú C, Bruix J. Prognosis of hepatocellular carcinoma: the BCLC staging classification. Semin Liver Dis 1999;19(3):32938.

6. Chevret S, Trinchet JC, Mathieu D, Rached AA, Beaugrand M, Chastang C. A new prognostic classification for predicting survival in patients with hepatocellular carcinoma: Grouped'Etude et de Traitement du CarcinomeHépatocellulaire. J Hepatol 1999;31(1):133-41.

7. Leung TW, Tang AM, Zee B, et al. Construction of the Chinese University Prognostic Index for hepatocellular carcinoma and comparison with the TNM staging system, the Okuda staging system, and the Cancer of the Liver Italian Program staging system: A study based on 926 patients. Cancer 2002;94(6):1760-69.

8. Kudo M, Chung H, Osaki Y. Prognostic staging system for hepatocellular carcinoma (CLIP score): its value and limitations, and a proposal for a new staging system, the Japan Integrated Staging Score (JIS score). J Gastroenterol 2003;38(3):207-15.

9. Ikai I, Takayasu K, Omata M, et al. A modified Japan Integrated Stage score for prognostic assessment in patients with hepatocellular carcinoma. J Gastroenterol 2006;41(9):884-92.

10. Okuda K, Ohtsuki T, Obata H, et al. Natural history of hepatocellular carcinoma and prognosis in relation to treatment. Study of 850 patients. Cancer 1985;56(4):918-28.
11. Tateishi R, Yoshida H, Shiina S, et al. Proposal of a new prognostic model for hepatocellular carcinoma: an analysis of 403 patients. Gut 2005;54(3):419-25.

12. Kamath PS, Wiesner RH, Malinchoc M, et al. A model to predict survival in patients with endstage liver disease. Hepatology 2001;33(2):46470.

13. El-Serag HB: Hepatocellular Carcinoma. N Engl J Med 2011;365:1118-27.

14. Bruix J1, Sherman M. Management of hepatocellular carcinoma. Hepatology 2005;42(5):1208-36.

15. Lei HJ, Chau GY, Lui WY, et al. Prognostic value and clinical relevance of the 6th Edition 2002 American Joint Committee on Cancer staging system in patients with resectable hepatocellular carcinoma. J Am Coll Surg 2006;203(4):42635 .

16. Buccheri G, Ferrigno D, Tamburini M. Karnofsky and ECOG performance status scoring in lung cancer: a prospective, longitudinal study of 536 patients from a single institution. Eur J Cancer 1996;32A(7):1135-41.

17. Vauthey JN, Dixon E, Abdalla EK, et al. Pretreatment assessment of hepatocellular carcinoma: expert consensus statement. HPB (Oxford) 2010;12(5):289-99.

18. Davila JA, Duan Z, McGlynn KA, El-Seraq HB. Utilization and outcomes of palliative therapy for hepatocellular carcinoma: apopulation-based study in the United States. J ClinGastroenterol 2012;46(1):71-7.

19. Clark HP, Carson WF, Kavanagh PV, Ho CP, Shen $\mathrm{P}$, Zagoria RJ. Staging and current treatment of hepatocellular carcinoma. Radiographics 2005;25(Suppl 1):S3-23.

20. El-Serag HB, Marrero JA, Rudolph L, Reddy KR. Diagnosis and treatment of hepatocellular carcinoma. Gastroenterology 2008;134(6):1752-63.

21. Roayaie S, Obeidat K, Sposito C, et al. Resection of hepatocellular cancer $=2 \mathrm{~cm}$ : results from two Western centers. Hepatology 2013;57(4):142635 .

22. Wang JH, Wang CC, Hung CH, Chen CL, Lu SN. Survival comparison between surgical resection and radiofrequency ablation for patients in BCLC very early/early stage hepatocellular carcinoma. J Hepatol 2012;56(2):412-8.

23. Peng ZW, Lin Xj, Zhang YJ, et al. Radiofrequency ablation versus hepatic resection for the treatment of hepatocellular carcinomas $2 \mathrm{~cm}$ or smaller: a retrospective comparative study. Radiology 2012;262(3):1022-33.

24. Mazzaferro V, Regalia E, Doci R, et al. Liver transplantation for the treatment of small hepatocellular carcinomasin patients with 
cirrhosis. N Engl J Med 1996;334(11):693-9.

25. Bruix J, Sherman M. Management oh hepatocellular carcinoma: An update. Hepatology 2011;53(3):1020-22.

26. Klintmalm GB. Liver transplantation for hepatocellular carcinoma: a registry reportof the impacto f tumor characteristics on outcome.Ann Surg 1998;228(4):479-90.

27. Yamamoto J, Iwatsuki S, Kosuge T, et al. Should hepatomas be treated with hepatic resection or transplantation? Cancer 1999;86(7):1151-58.

28. Farinati F, Sergio A, Baldan A, et al. Early and very early hepatocellular carcinoma: when and how much do staging and choice of treatment really matter? A multi-center study. BMC Cancer 2009;9:33.

29. Dhir M, Lyden ER, Smith LM, Are C. Comparison of outcomes of transplantation and resection in patients with early hepatocellular carcinoma: a meta-analysis. HPB (Oxford) 2012;14(9):63545.

30. Iwatsuki S, Dvorchik I, Marsh JW, et al. Liver transplantation for hepatocellular carcinoma: a proposal of a prognostic scoring system. J Am Coll Surg 2000;191(4):389-94.

31. Tamura S, Kato T, Berho M, et al. Impact of histological grade of hepatocellular carcinoma on the outcomes of liver transplantation. Arch Surg 2001;136(1):25-30.

32. Hemming AW, Cattral MS, Reed AI, Van Der Werf WJ, Greig PD, Howard RJ: Liver transpolantation for hepatocellular carcinoma. Ann Surg 2001;233(5):652-9.

33. Jonas S, Herrmann M, Rayes N, et al. Survival after liver transplantation for hepatocellular carcinoma in cirrhosis according to the underlying liver disease. Transplant Proc 2001;33(7-8):3444-5.

34. Figueras J, Ibañez L, Ramos E, et al. Selection criteria for liver transplantation in earlystage hepatocellular carcinoma with cirrhosis: results of a multicenter study. Liver Transpl 2001;7(10):877-83.

35. Yao FY, Ferrell L, Bass NM, et al. Liver transplantation for hepatocellular carcinoma: expansion of the tumor size limits does not adversely impact survival. Hepatology 2001;33(6):1394-403.

36. Gondolesi GE, Roayaie S, Muñoz L, et al. Adult living donor liver transplantation for patients with hepatocellular carcinoma: extending UNOS priority criteria. Ann Surg 2004;239(2):142-9.

37. Zavaglia C, De Carlis L, Alberti AB, et al. Predictors of long-term survival after liver transplantation for hepatocellular carcinoma. Am J Gastroenterol 2005;100(12):2708-16.

38. Takada Y, Ueda M, Ito T, et al. Living donor liver transplantation as a second-line therapeutic strategy for patients with hepatocellular carcinoma. Liver Transpl 2006;12(6):912-9.

39. Cherqui D, Laurent A, Mocellin N, et al. Liver resection for transplantable hepatocellular carcinoma: long-term survival and role of secondary liver transplantation. Ann Surg 2009;250(5):738-46.

40. Coelho GR, Vasconcelos KF, Vasconcelos $\mathrm{JB}$, et al. Orthotopic liver transplantation for hepatocellular carcinoma: one center's experience in the Northeats of Brazil. Transplant Proc 2009;41(5):1740-2.

41. Lee KK, Kim DG, Moon IS, Lee MD, Park JH. Liver transplantation versus liver resection for the treatment of hepatocellular carcinoma. J SurgOncol 2010;101(1):47-53.

42. Vibert E, Azoulay D, Hoti E, et al. Progression of alphafetoprotein before liver transplantation for hepatocellular carcinoma in cirrhotic patients: a critical factor. Am J Transplant 2010;10:129-37.

43. Koniaris LG, Levi DM, Pedroso FE, et al. Is surgical resection superior to transplantation in the treatment of hepatocellular carcinoma? Ann Surg 2011;254(3):527-37.

44. Sandhu L, Sandroussi C, Guba M, et al. Live donor versus deceased donor liver transplantation for hepatocellular carcinoma: comparable survival and recurrence. Liver Transpl 2012;18(3):31522.

45. Rahman A, Assifi MM, Pedroso F, et al. Is Resection Equivalent to Transplantation for Early Cirrhotic Patients with Hepatocellular Carcinoma? A Meta-Analysis. Journal of Gastrointestinal Surgery 2012;16 (10): 1897909.

46. Onaca N, Davis GL, Jennings LW, Goldstein RM, Klintmalm GB. Improved results of transplantation for hepatocellular carcinoma: A report from the international registry of hepatic tumors in liver transplantation.LiverTransp 2009;15(6):574-80.

47. Scientific Registry of Transplant Recipients SRTR. 2011 Annual Data Report.http://srtr. transplant.hrsa.gov/annual_reports/2011/ default.aspx (accessed 24 Jun 2014).

48. Sharma P, Balan V, Hernandez JL, et al. Liver transplantation for hepatocellular carcinoma: The MELD impact. LiverTranspl 2004;10(1):3641.

49. Adam R, Karam V, Delvart V, et al. Evolution of indications and results of liver transplantation in Europe. A report from the European Liver Transplant Registry (ELTR).J Hepatol 2012;57(3):675-88.

50. Toso C, Dupuis-Lozeron E, Majno P, et al. A model for dropout assessment of candidates with or without hepatocellular carcinoma on a 
common liver transplant waiting list. Hepatology 2012;56(1):149-56.

51. Avolio AW, Cillo U, Salizzoni M, et al. Balancing donor and recipient risk factors in liver transplantation: the value of D-MELD with particular reference to $\mathrm{HCV}$ recipients. Am J Transplant 2011;11(12):2724-36.

52. Avolio AW, Agnes S, Cillo U, et al. http://www.DMELD.com, the Italian survival calculator to optimize donor to recipient matching and to identify the unsustainable matches in liver transplantation. Transpl Int 2012;25(3):294301.

53. Vitale A, Morales RR, Zanus G, et al. Barcelona Clinic Liver Cancer staging and transplant survival bene?t for patients with hepatocellular carcinoma: a multicentre, cohort study. Lancet Oncol 2011;12(7):654-62.

54. Bruix J, Castells A, Bosch J, et al. Surgical resection of hepatocellular carcinoma in cirrhotic patients: prognostic value of preoperative portal pressure.Gastroenterology 1996;111(4):101822.

55. Llovet JM, Fuster J, Bruix J. Intention-totreat analysis of surgical treatment for early hepatocellular carcinoma: Resection versus transplantation. Hepatology 1999;30(6):143440.

56. Bellavance EC, Lumpkins KM, Mentha $\mathrm{G}$, et al. Surgical management of earlystage hepatocellular carcinoma: resection or transplantation? J GastrointestSurg 2008;12(10):1699-708.

57. Emond JC, Samstein B, Renz JF. A critical evaluation of hepatic resection in cirrhosis: optimizing patient selection and outcomes. World J Surg 2005;29(2):124-30.

58. Hsieh CB, Chung KP, Chu CM, et al. Appropriate liver resection type for patients with the American joint committee on cancer classification $\mathrm{T} 1$ and T2 hepatocellular carcinoma.Eur J SurgOncol 2011;37(6):497-504.

59. Chen MF, Hwang TL, Jeng LB, Wang CS, Jan YY, Chen SC. Postoperative recurrence of hepatocellular carcinoma in patients undergoing hepatic resection. ArchSurg 1994;129:738-42.

60. Zhou XD, Tang ZY, Yang BH, et al. Experience of 1000 patients who underwent hepatectomy for small hepatocellular carcinoma. Cancer 2001;91(8):1479-86.

61. Grazi GL, Ercolani G, Pierangeli F, etal. Improved results of liver resection for hepatocellular carcinoma on cirrhosis give the procedure added value. Ann Surg 2001;234(1):71-8.

62. Yamamoto J, Okada S, Shimada $K$, et al. Treatment strategy for small hepatocellular carcinoma: comparison of long-term results after percutaneous ethanol injection therapy and surgical resection. Hepatology 2001;34(4Pt1):707-13.

63. Poon RT, Fan ST, Lo CM, Liu CL, Wong J. Long-term survival and pattern of recurrence after resection of small hepatocellular carcinoma in patients with preserved liver function: implications for a strategy of salvage transplantation. Ann Surg 2002;235(3):373-82.

64. Wayne JD, Lauwers GY, Ikai I, et al. Preoperative predictors of survival after resection of small hepatocellular carcinomas. Ann Surg 2002;235(5):722-30.

65. Grazi GL, Cescon M, Ravaiolli M, et al. Liver resection for hepatocellular carcinoma encirrhotics and noncirrhotics. Evaluation of clinicopathologic features and comparison of risk factors for long-term survival and tumour recurrence in a single centre. Aliment PharmacolTher 2003;2:119-29.

66. Ercolani G, Grazi GL, Ravaiolli M, et al. Liver resection for hepatocellular carcinoma on cirrhosis: univariate and multivariate analysis of risk factors for intrahepatic recurrence. Ann Surg 2003;237(4):536-43.

67. $\mathrm{Hu} \mathrm{RH}, \mathrm{Ho} \mathrm{MC}, \mathrm{Wu} \mathrm{YM}, \mathrm{Yu}$ SC, Lee PH. Feasibility of salvage liver transplantation for patients with recurrent hepatocellular carcinoma. Clin Transplant 2005;19(2):175-80.

68. Pawlik TM, Poon RT, Abdalla EK, et al. Critical appraisal of the clinical and pathologic predictors of survival after resection of large hepatocellular carcinoma. Arch Surg 2005;140(5):450-7.

69. Wu CC, Cheng SB, Ho WM, Chen JT, Liu TJ, P'eng FK. Liver resection for hepatocellular carcinoma in patients with cirrhosis. Br J Surg 2005;92(3):348-55.

70. Taura K, Ikai I, Hatano E, et al. Influence of coexisting cirrhosis on outcomes after partial hepatic resection for hepatocellular carcinoma fulfilling the Milan criteria: an analysis of 293 patients. Surgery 2007;142(5):685-94.

71. Yamashita $\mathrm{Y}$, Taketomi A, Itoh $\mathrm{S}$, et al. Longterm favorable results of limited hepatic resections for patients with hepatocellular carcinoma: 20 years of experience. J Am Coll Surg 2007;205(1):1926.

72. Fuks D, Dokmak S, Paradis V, Diouf M, Durand F, Belghiti J. Benefit of initial resection of hepatocellular carcinoma followed by transplantation in case of recurrence: An intention-to-treat analysis. Hepatology 2012;55:132-40.

73. Hasegawa K, Kokudo N, Makuuchi M, et al. Comparison of resection and ablation for hepatocellular carcinoma: a cohort study based on a Japanese nationwide survey. J Hepatol 2013;58(4):724-9. 
74. Chan KY, Wong CM, Kwan JS, et al.Genomewide association study of hepatocellular carcinoma in Southern Chinese patients with chronic hepatitis B virus infection. PLoS ONE 2011;6(12):e28798.

75. Wright JC, Weinstein MC. Gains in Life Expectancy from Medical Interventions Standardizing Data on Outcomes. N Engl J Med 1998;339:380-6.

76. Llovet JM, Schwartz M, Mazzaferro V. Resection and liver transplantation for hepatocellular carcinoma. SeminLiver Dis 2005;25(2):181200.

77. Margarit C, Escartín A, Castells L, Vargas V, Allende E, Bilbao I. Resection for hepatocellular carcinoma is a good option in Child-TurcottePugh class A patients with cirrhosis who are eligible for liver transplantation. LiverTranspl 2005;11(10):1242-51.

78. Kamiyama $\mathrm{T}$, Nakanishi $\mathrm{K}$, Yokoo $\mathrm{H}$, et al. Recurrence patterns after hepatectomy of hepatocellular carcinoma: implication of Milan criteria utilization. Ann Surg Oncol 2009;16(6):1560-71.

79. Facciuto ME, Koneru B, Rocca JP, et al. Surgical treatment of hepatocellular carcinoma beyond Milan criteria. Results of liver resection, salvage transplantation, and primary liver transplantation. Ann Surg Oncol 2008;15(5):1383-91.

80. Ikegami T, Shimada M, Imura S, et al. The timing of liver transplantation after primary hepatectomy for hepatocellular carcinoma: a special reference to recurrence pattern and Milan criteria. Transplantation 2008;86:641-6.

81. Vilana R, Bruix J, Bru C, Ayuso C, Solé M, Rodés J. Tumor size determines the efficacy of percutaneous etanol injection for the treatment of small hepatocellular carcinoma.Hepatology 1992;16(2):353-7.

82. Meloni F, Lazzaroni S, Livraghi T. Percutaneous etanol injection: sigle session treatment.Eur $\mathrm{J}$ Ultrasound 2001;13(2):107-15.

83. Camma C, Di Marco V, Orlando A, et al. Treatment of hepatocellular carcinoma in compensated cirrhosis with radiofrequency thermal ablation: a prospective study. J Hepatol 2005;42:535-40.

84. Lencioni RA, Allgaier HP, Cioni D, et al. Small hepatocellular carcinoma in cirrhosis: randomized comparison of radio-frequency thermal ablation versus percutaneous ethanol injection. Radiology 2003;228(1):235-40.

85. Shiina $S$, Teratani $T$, Obi $S$, et al. A randomized Controlled Trial of Radiofrequency Ablation With Ethanol Injection for Small Hepatocellular Carcinoma. Gastroenterology 2005;129(1):12230.
86. Lin SM, Lin CJ, Lin CC, Hsu CW, Chen YC. Randomisedcontroles trial comparing percutaneous radiofrequency termal ablation, percutaneous ethanol injection, and percutaneous acetic acid injection to treat hepatocellular carcinoma of $3 \mathrm{~cm}$ or less. Gut 2005;54(8):1151-6.

87. Brunello F, Veltri A, Carucci $P$, et al. Radiofrequency ablation versus etanol injection for early hepatocellular carcinoma: randomized controlled trial.Scand J Gastroenterol 2008;43(6):727-35.

88. Bouza C, López-Cuadrado, Alcázar R, SazParkinson Z, Amate JM. Meta-analysis of percutaneous radiofrequency ablation versus etanol injection in hepatocellular carcinoma. BMC Gastroenterology 2009;9:31.

89. LivraghiT,LazzaroniS, MeloniF. Radiofrequency thermal ablation of hepatocellular carcinoma. Eur J Ultrasound 2001; 13(2):159-66.

90. Peng ZW, Zhang YJ, Chen MS, et al. Radiofrequency Ablation With or Without Transcatheter Arterial Chemoembolization in the Treatment of Hepatocellular Carcinoma: A Prospective Randomized Trial. J Clin Oncol 2013;31:426-32. 
Access full text article on other devices

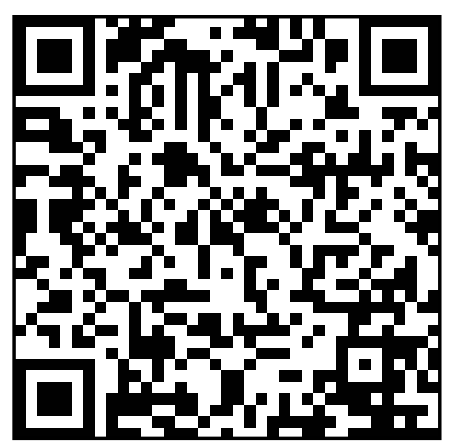

Access PDF of article on other devices

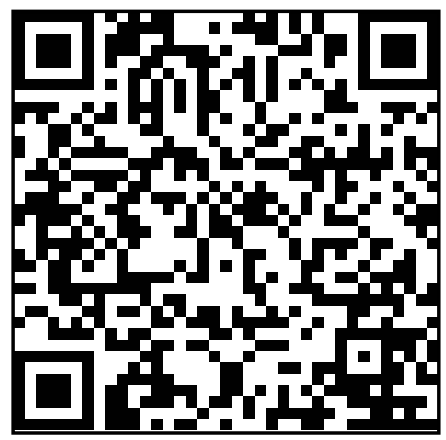

